\title{
Ocorrência do ácaro vermelho europeu Panonychus ulmi (Koch) (Tetranychidae) associado à cultura da videira no Rio Grande do Sul, Brasil
}

\author{
European red spider mite Panonychus ulmi (Koch) (Tetranychidae) occurrence of \\ vineyards in Rio Grande do Sul, Brazil
}

\author{
Noeli Juarez Ferla ${ }^{\mathrm{I}}$ Marcos Botton ${ }^{\mathrm{II}}$
}

\section{-NOTA-}

\section{RESUMO}

Neste artigo é descrita ocorrência e o dano causado pelo ácaro vermelho europeu Panonychus ulmi (Koch) associado à cultura da videira. As coletas foram realizadas na safra 2005-2006 em Vitis vinifera L. da cultivar Merlot, nos municípios de Bento Gonçalves e Candiota, no Estado do Rio Grande do Sul, Brasil. As folhas infestadas apresentaram bronzeamento, com manchas avermelhadas na face adaxial, resultando na queda prematura das mesmas. Esse é o primeiro registro do ácaro vermelho europeu danificando a cultura da videira no Rio Grande do Sul.

Palavras-chave: Acari, uva, uva vinífera, Vitaceae.

\section{ABSTRACT}

The occurrence and the damage caused for the European red spider mite Panonychus ulmi (Koch) associated to the culture of the grapevine are described. The collections had been carried through in 2005-2006 seasons in Vitis vinifera L. of cultivating Merlot in Bento Gonçalves and Candiota counties, in the state of Rio Grande do Sul, Brazil. The infested leaves had presented bronzing, with spots redly in the adaxial face resulting in the premature fall. This is the first register of the European red mite damaging the culture of the grapevine in Rio Grande do Sul.

Key words: Acari, grape, grapevine, Vitaceae.

A videira (Vitis vinifera L.: Vitaceae) é cultivada em praticamente todas as regiões do Brasil. Ela foi introduzida no país por imigrantes europeus que se estabeleceram no Estado do Rio Grande do Sul, sendo que atualmente a região da Serra Gaúcha concentra a maior parte dos vinhedos e vinícolas. Entretanto, um aumento significativo de vinhedo e vinícolas está sendo observado na fronteira oeste do Rio Grande do Sul, principalmente com varietais viníferas. Doenças, insetos e ácaros são problemas comuns enfrentados pelos viticultores nas diferentes regiões produtoras. Entre os ácaros, destacam-se Eriophyidae, Tarsonemidae e Tetranychidae (REIS \& MELO, 1984; SCHRUFT, 1985; SORIA et al., 1985; MONTEIRO, 1994; DUSO \& DE LILLO, 1996; BOTTON et al., 2003).

Na Europa, os tetraniquídeos passaram a ter maior importância a partir da década de 1950, com a utilização de agrotóxicos e alterações de práticas culturais em uvas viníferas (SCHRUFT, 1985). Várias espécies desse grupo são citadas na cultura da videira (JEPPSON et al., 1975; SCHRUFT, 1985; BOLLAND et al., 1998). Entre eles, destaca-se Panonychus ulmi (Koch) (ácaro vermelho europeu). Essa espécie tem como hospedeiros principais frutíferas e arbustos da família Rosaceae (BAKER \& TUTTLE, 1994; BOLLAND et al., 1998). Eles são encontrados na face abaxial das folhas e seu ataque é particularmente prejudicial no início da primavera e no final do verão europeu. Na primavera, seu ataque pode provocar queda de folhas, prejudicando o desenvolvimento das flores e dos brotos. O nível de dano econômico nesta estação inicia quando $60-70 \%$ das folhas estão infestadas pelo ácaro. No final do verão, altas populações podem causar bronzeamento das folhas e afetar a qualidade dos frutos (SCHRUFT, 1985), sendo

IMuseu de Ciências Naturais, Centro Universitário UNIVATES, CP 155, 95900-000, Lajeado, RS, Brasil. E-mail: njferla@univates.br.
Autor para correspondência.

"Embrapa Uva e Vinho, CP 130, 95700-000, Bento Gonçalves, RS, Brasil. 
que a percentagem de folhas com um ou mais ácaros não pode exceder 30-45\%, para evitar um ataque nocivo desta espécie no final do verão ou no outono (BAILLOD et al., 1979). Para o controle de $\boldsymbol{P}$. ulmi, são utilizados acaricidas específicos, tais como ethion, parathion, thrithion e thiodan. Entretanto, ácaros predadores Phytoseiidae exercem um papel importante no controle biológico daquela praga na região citada (SCHRUFT, 1985).

No Brasil, os únicos tetraniquídeos sobre videiras citados são Oligonychus mangiferous Rahman \& Pundjab, Tetranychus desertorum Banks e Allonychus braziliensis (Mcgregor) (SORIA et al., 1985; BOTTON et al., 2003). Oligonychus mangiferous foi observado causando queima prematura de folhas de videira (REIS \& MELO, 1984; SORIA et al., 1985). Até o momento, P. ulmi não foi citado em relação a videiras na Serra Gaúcha ou no Brasil. Entretanto, P. ulmi apresenta importância econômica na cultura da maçã (MONTEIRO, 2002). Nessa cultura, ele causa bronzeamento das folhas e, em ataque severo, reduz o crescimento dos ramos, o tamanho e a coloração dos frutos e o teor de açúcar, além de provocar a queda prematura das folhas, interferindo na floração e na frutificação do ano seguinte (MCMURTRY et al., 1970; CROFT, 1975; LORENZATO, 1987).

Neste trabalho, é relatada a presença de $\boldsymbol{P}$. ulmi e o dano provocado em videiras da varietal Merlot nos municípios de Bento Gonçalves e Candiota, Rio Grande do Sul. As folhas foram coletadas na safra 20052006 e levadas ao laboratório para a retirada e a montagem dos ácaros. Os ácaros foram montados em meio de Hoyer (JEPPSON et al., 1975) e mantidos em estufa para a secagem do meio e fixação, distensão e clarificação dos espécimes.

Foram encontrados espécimes de $\boldsymbol{P}$. ulmi em Merlot. Na fêmea, as setas dorsais do corpo são robustas, espiculadas e sobre tubérculos, com o comprimento da maioria estendendo-se além das bases das setas das filas seguintes (exceto ve, c3 e f12). Seta $f 2$ mais longa que $f 1$ (Figura 1a-g). Há setas dúplices no tarso I distais e próximas, empódio unciforme com três pares de pêlos ventrais e dois pares de setas paranais. O macho é semelhante à fêmea, porém apresenta o opistossoma afilado. O edeago é sigmóide dorsalmente.

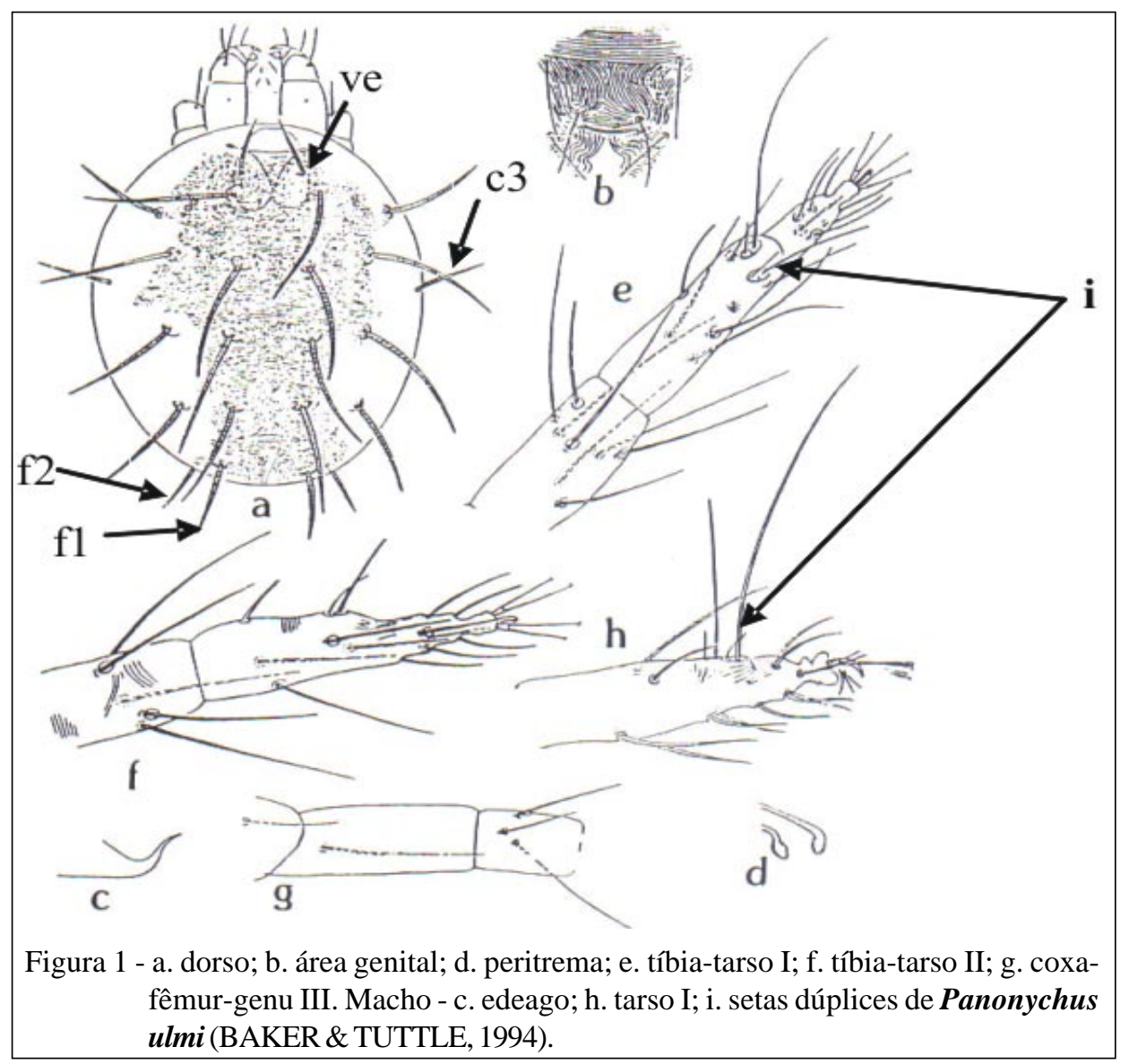

Ciência Rural, v.38, n.6, set, 2008. 
Os ovos estriados apresentam pedúnculo na parte superior, sendo observados na face abaxial das folhas, próximo das nervuras. Maior número de ovos foi observado nas folhas novas das plantas. Os adultos estavam presentes tanto na face abaxial quanto na face adaxial das folhas.

As folhas apresentavam bronzeamento, com manchas avermelhadas na face adaxial (Figura 2A). $\mathrm{O}$ vinhedo apresentou bronzeamento precoce com queda prematura de folhas (Figura 2B). Embora o dano não tenha sido quantificado, as lesões produzidas por P. ulmi provocam menor atividade fotossintética no pós-colheita, reduzindo o acúmulo de reservas na entressafra.
Panonychus ulmi está presente nos pomares de maçã durante todo o período vegetativo, com predominância nos meses de janeiro e fevereiro, período com temperaturas mais elevadas e baixa umidade relativa (LORENZATO, 1987). Nessa cultura, o aumento populacional do ácaro P. ulmi tem sido associado à utilização intensiva e indiscriminada de produtos químicos não específicos como inseticidadas e fungicidas (LORENZATO \& MELZER, 1984).

A dispersão de $\boldsymbol{P}$. ulmi pode ser resultante da proximidade da cultura da maçã com os vinhedos na região da Serra Gaúcha. Em Candiota, possivelmente, a disseminação tenha ocorrido por trânsito de material

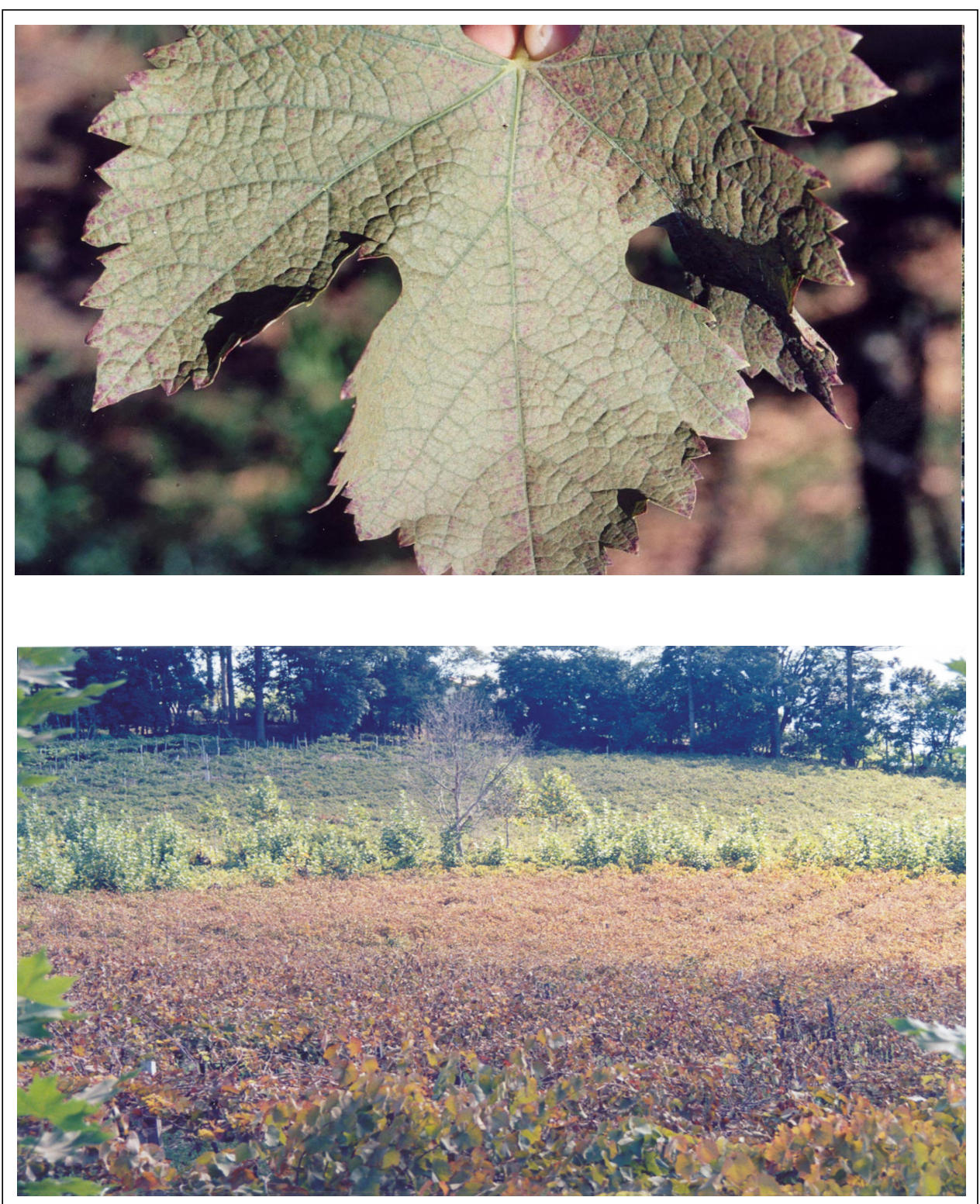

Figura 2 - Danos provocados por Panonychus ulmi em folhas de videira (A) e em parreirais da varietal Cabernet Sauvignon, no município de Bento Gonçalves, na safra de 2005-2006 (B).

Ciência Rural, v.38, n.6, set, 2008. 
vegetativo infestado tanto do Brasil como do Exterior. Não se descarta a hipótese de que o uso de produtos químicos nos vinhedos, com destaque para fungicidas não-seletivos, tenha reduzido a população de inimigos naturais, permitindo a proliferação do ácaro vermelho no cultivo. A constatação de $\boldsymbol{P}$. ulmi na cultura da videira e os danos observados indicam que o ácaro vermelho deve ser inserido no programa de manejo integrado de pragas da cultura da videira no Estado do Rio Grande do Sul. Além disso, é importante que os técnicos reconheçam a presença dessa espécie nos vinhedos, diferenciando-o de Tetranychus urticae Koch (ácaro rajado) para fins de definição das estratégias de controle.

\section{REFERÊNCIAS}

BAKER, E.W.; TUTTLE, D.M. A guide to the spider mites (Tetranychidae) of the United States. House West Bloomfield: Indira Publishing, 1994. 347p.

BAILLOD, M. et al. L'estimation du risqué provoque par l'acarien rouge (Panonychus ulmi Koch) et l'acarien des charmilles (Eotetranychus carpini Oud.) en viticulture. Revue suisse de viticulture, d'arboriculture et d'horticulture, v.11, p.123-130, 1979.

BOLLAND, H.R. et al. World catalogue of the spider mite family (Acari: Tetranychidae). Brill: Leiden, 1998. 392p.

BOTTON, M. et al. Pragas. In: FAJARDO, T.V.M. (Ed.). Uvas para processamento: fitossanidade. Brasilia DF: Embrapa Informação Tecnológica, 2003. p.82-107. (Frutas do Brasil, 35).

CROFT, B.A. Integrated control of apple mites. East Lansing: Michigan state University, Cooperative Extension Service, 1975. 12p. (Extension Bulletin, E-825)

DUSO, C.; DE LILLO, E. Grape. In: LINDQUIST, E.E. et al. (Eds.). Eriophyoid mites. Amsterdan: Elsevier, 1996. p. 571-582.
JEPPSON, L.R. et al. Mites injurious to economic plants. Berkeley: University of California, 1975. 614p.

LORENZATO, D. Controle biológico de ácaros fitófagos na cultura da macieira no município de Farroupilha - RS. Agronomia Sulriograndense, v.23, n.2, p.167-183, 1987.

LORENZATO, D.; MELZER, R. Efeitos dos acaricidas e inseticidas no controle do ácaro vermelho europeu Panonychus ulmi (Koch), na cultura da macieira (Malus domesticus Bork). Agronomia Sulriograndense, v.20, n.2, p.135-151, 1984.

McMURTRY, J. A. et al. Ecology of tetranychid mites and their natural enemies: a review. 1. Tetranychid enemies: their biological characters and the impact of spray practices. Hilgardia, v.40, n.11, p.331-390, 1970.

MONTEIRO, L.B. Ocorrência de Polyphagotarsonemus latus (Banks) (Acari: Tarsonemidae) em videira em Bento Gonçalves - RS, Brasil. Anais da Sociedade Entomológica do Brasil, v.23, n.2, p.349-350, 1994.

MONTEIRO, L.B. Manejo integrado de pragas em macieira no Rio Grande do Sul II. Uso de Neoseiulus californicus para o controle de Panonychus ulmi. Revista Brasileira de Fruticultura, v.24, n.2, p.395-405, 2002.

REIS, P.R.; MELO, L.A.S. Pragas da videira. Informe Agropecuário, v.110, n.117, p.68-72, 1984.

SCHRUFT, G.A. Grape. In: HELLE, W.; SABELIS, M.W. Spider mites: their biology, natural enemies and control. Amsterdan: Elsevier, 1985. p.359-366.

SORIA, S. DE J. et al. Ocorrência de ácaro branco ou tropical e outros de importância agrícola em vinhedos do Rio Grande do Sul. In: CONGRESSO BRASILEIRO DE VITICULTURA E ENOLOGIA, 7., 1985, Bento Gonçalves, RS. Anais... Bento Gonçalves: Embrapa Uva e Vinho. 1993. p.69-71. 